\title{
NONLINEAR ELLIPTIC EQUATIONS WITH SMALL BMO COEFFICIENTS IN NONSMOOTH DOMAINS IN GENERALIZED MORREY SPACES
}

\section{T. S. GADJIEV* AND V. S. GuliYeV}

Abstract. We obtain the generalized Sobolev-Morrey spaces $W_{p, \varphi}^{1}(\Omega)$ estimate for weak solutions of a boundary value problem for nonlinear elliptic equations with $B M O$ coefficients in nonsmooth domains. We investigate regularity of the weak solutions in generalized Morrey spaces $M_{p, \varphi}(\Omega)$. The nonlinearity has sufficiently small $B M O$ seminorm and the boundary of the domain is sufficiently flat.

Mathematics subject classification (2020): 35J25, 35B40, 42B20, 42B25.

Keywords and phrases: Nonlinear elliptic equations, generalized Sobolev-Morrey spaces, maximal function, Reifenberg flat domain, small $B M O$.

\section{REFERENCES}

[1] A. Akbulut, V. S. Guliyev, R. Mustafayev, On the boundedness of the maximal operator and singular integral operators in generalized Morrey spaces, Math. Bohem. 137 (1) 2012, 27-43.

[2] P. Auscher, M. QAfaonu, Observations on $W^{1, p}$ estimates for divergence elliptic equations with VMO coefficients, Boll. Unione Mat. Ital. Sez. B Artic Ric. Mat. (8) 5(2) (2002), 487-509.

[3] V. Burenkov, A. Gogatishvili, V. S. Guliyev, R. Mustafayev, Boundedness of the fractional maximal operator in local Morrey-type spaces, Complex Var. Elliptic Equ. 55 (8-10) (2010), 739-758.

[4] S. Byun, L. WANG, Elliptic equations with BMO coefficients in Reifenberg domain, Comm. Pure Appl. Math. 57 (10) (2004), 1283-1310.

[5] S. Byun, L. WANG, Parabolic equations in time dependent Reifenberg domains, Adv. Math. 212 (2) (2007), 797-818.

[6] S. Byun, L. WANG, S. ZHOU, Nonlinear elliptic equations with BMO coefficients in Reifenberg domain, J. Funct. Anal. 250 (1) (2007), 167-196.

[7] L. A. CAFFARELLI, Interior a priori estimates for solutions of fully nonlinear equations, Ann. of Math. 130 (2) (1989), 189-213.

[8] F. Chiarenza, M. Frasca, P. Longo, $W_{2, p}$-solvability of Dirichlet problem for nondivergence elliptic equations with VMO coefficients, Trans. Amer. Math. Soc. 336 (1993), 841-853.

[9] E. Di Benedetto, J. MANFREDI, On the higher integrabilty on the gradient of weak solutions of certain degenerate elliptic system, Amer. J. Math. 115 (5) (1993), 1107-1134.

[10] Y. Ding, D. YANG, Z. ZHOU, Boundedness of sublinear operators and commutators on $L^{p, w}\left(\mathbb{R}^{n}\right)$, Yokohama Math. J. 46 (1) (1998), 15-27.

[11] G. Di FAZIO, $L^{p}$ estimates for divergence form elliptic equations with discontimous coefficients, Boll. Unione Mat. Ital. A (7) 10 (2) (1996), 409-420.

[12] G. Di FAZIO, D. I. HAKIM, Y. SAWANO, Elliptic equations with discontinuous coefficients in generalized Morrey spaces, Eur. J. Math. 3 (3) (2017), 728-762.

[13] T. S. Gadjiev, Sh. Galandarova, V. S. Guliyev, Regularuty in generalized Morrey spaces of solutions to higher order nondivergence elliptic equations with VMO coefficients, Electron. J. Qual. Theory Differ. Equ. Paper No. 55 (2019), 17 pp.

[14] T. S. Gadjiev, V. S. Guliyev, K. G. Suleymanova, The Dirichlet problem for the uniformly elliptic equation in generalized weighted Morrey spaces, Studia Sci. Math. Hungar. 57 (1) (2020), 68-90. 
[15] V. S. GULIYEV, Integral operators on function spaces on the homogeneous groups and on domains in $\mathbb{G}$, Doctor's degree dissertation, Moscow, Mat. Inst. Steklov, 1994, 1-329, (Russian).

[16] V. S. GULIYEV, Function spaces, integral operators and two weighted inequalities on homogeneous groups. Some applications, Baku. 1999, 1-332, (Russian).

[17] V. S. GuLIYEV, Boundedness of the maximal, potential and singular operators in the generalized Morrey spaces, J. Inequal. Appl. Art. ID 503948, (2009), 20 pp.

[18] V. S. Guliyev, S. S. Aliyev, T. Karaman, P. Shukurov, Boundedness of sublinear operators and commutators on generalized Morrey spaces, Integral Equations Operator Theory, 71 (3), (2011), $1-29$.

[19] V. S. Guliyev, T. S. Gadjiev, Sh. Galandarova, On solvability Dirichlet problem for higher order elliptic equation, Electron. J. Qual. Theory Differ. Equ., Paper No. 71 (2017), 17 pp.

[20] V. S. GuliyeV, T. S. GAdjieV, A. Serbetci, The Dirichlet problem for the uniformly higher-order elliptic equations in generalized weighted Sobolev-Morrey spaces, Nonlinear Studies, 26 (4) (2019), 831-842.

[21] V. S. Guliyev, L. Softova, Global regularity in generalized Morrey spaces of solutions to nondivergence elliptic equations with VMO coefficients, Potential Anal. 38 (3) (2013), 843-862.

[22] V. S. Guliyev, L. Softova, Generalized Morrey estimates for the gradient of divergence form parabolic operators with discontinuous coefficients, J. Differential Equations 259 (6) (2015), 23682387.

[23] V. S. Guliyev, M. N. Omarova, L. Softova, The Dirichlet problem in a class of generalized weighted Morrey spaces, Proc. Inst. Math. Mech. Natl. Acad. Sci. Azerb. 45 (2) (2019), 270-285.

[24] P. Hajlasz, O. Martio, Traces of Sobolev functions on fractal type sets and characterization of extension domains, J. Funct. Anal. 143 (1) (1997), 221-246.

[25] J. Kinnunen, S. Zhou, A local estimate for nonlinear equations with discontinuous coefficients, Comm. Partial Differential Equations 24 (11-12) (1999), 2043-2068.

[26] J. Kinnunen, S. ZHOU, A boundary estimates for nonlinear equations with discontinuous coeffcients, Differential Integral Equations 14 (4) (2001), 475-492.

[27] C. B. Morrey, On the solutions of quasilinear elliptic partial differential equations, Trans. Amer. Math. Soc. Soc. 43 (1) (1938), 126-166.

[28] T. Mizuhara, Boundedness of some classical operators on generalized Morrey spaces, Harmonic Anal. Proc. Conf. Sendai/Jap. 1990, ICM-90 Satell. Conf. Proc., 183-189.

[29] J. Peetre, On the theory $L_{p}$, J. Func. Anal. 4 (1969), 71-87.

[30] E. NAKAI, Hardy-Littlewood maximal operator, singular integral operators and the Reisz potentials on generalized Morrey spaces, Math. Nachr. 166 (1994), 95-103.

[31] E. NAKAI, Orlicz-Morrey spaces and the Hardy-Littlewood maximal function, Studia Math. 188 (3) (2008), 193-221.

[32] S. NAKAMURA, Y. SAWANO AND H. TANAKA, The fractional operators on weighted Morrey spaces, J. Geom. Anal. 28 (2) (2018), 1502-1524.

[33] D. Palagachev, L. Recke, L. Softova, Applications of the differential calculus to nonlinear elliptic operators with discontinuous coefficients, Math. Ann. 336 (3) (2006), 617-637.

[34] Y. SAWANo, Generalized Morrey spaces for non-doubling measures, Nonlinear Differential Equations Appl. 15 (4-5) (2008), 413-425.

[35] Y. SAWANO, A thought on generalized Morrey spaces, ArXiv preprint arXiv:1812.08394v1, 2018, 78 pp.

[36] L. Softova, Singular integrals and commutators in generalized Morrey spaces, Acta Math. Sin. (Engl. Ser.) 22 (2006), 757-766.

[37] L. Softova, Singular integral operators in Morrey spaces and interior regularity of solutions to systems of linear PDE's, J. Global Optim. 40 (1-3) (2008), 427-442.

[38] T. Toro, Doubling and flatness: geometry of meansures, Notices Amer. Math. Soc. 44 (9) (1997), 1087-1094.

[39] E. REIFENBERG, Solutions of the Platean problem for $m$-dimensional surfaces of varying topological type, Acta. Math. 104 (1960), 1-92. 